\title{
UNSETTLING RELATIONS: DISRUPTING THE ETHICAL SUBJECT IN FAN STUDIES RESEARCH
}

Natasha Whiteman, University of Leicester

ABSTRACT

This paper takes as its focus the strategies by which ethical stances are established and legitimised in fan studies writing. It argues that, as a matter of ethics, such stances should always be placed under interrogation. This can be achieved by disrupting the entities that are often invoked in claims about what constitutes ethical practice in research - ones that may otherwise quickly become naturalised points of reference. Using as an exemplar Busse \& Hellekson's articulation of the 'fans first' principle, the paper considers how ethical positions become sedimented and normalised within academic fields of practice. In doing so, the paper develops some counter-principles for an ethical destabilisation and (where necessary) dismantling of received ethical subjectivities in fan studies research.

\section{KEYWORDS}

Disruption, Research Ethics, Fans First, Fan Studies, Objectification, Participation.

\section{INTRODUCTION:}

The following approach to the interrogation of ethical stances in fan studies research establishes a particular methodological "attitude" (Dowling and Brown, 2009), one that suggests that it is productive to try to "remove from common sense" (Fuchs, 2009, 12) in our thinking about ethics. Rather than just "polishing" our methodological glasses (Evans and Stasi, 2014, after Hammersley) in order to "see" more ethically, my suggestion is that it may be more productive to engage in something akin to Garfinkel's breaching experiments (1967); exercises that aim to unsettle conventional thinking. In a similar manner, this article aims to encourage a disruptive perspective on our ethical thinking by examining the moves made in the 
negotiation of ethical issues in fan studies research, and dismantling the entities and assumptions that these invoke. Adopting this attitude may serve to challenge ethical positions if they are presented in research as self-evident - for example those that are presented as founded on natural or inherent values or virtues (Whiteman, 2012).

In arguing for an unsettling of ethical stances, this paper shares a concern with "distance" that has been expressed by other fan studies researchers. Here, however, my objective is not distance from the object of research (Larsen and Zubernis, 2012), or fan/academic orientations (Hills, 2012a), but an interest in how we might achieve rupturing breaks from our own ethical positioning when reflecting upon, and staking claims about ethics. In exploring this, I want to shift attention away from more familiar discussions, such as the ethical implications of the "problem of positioning" in negotiating fan/scholar subjectivities (see Zubernis and Larsen, 2012; 2013), the reporting of ethical decision-making in accounts of fieldwork (see, for example, Williams, 2015; Phillips, 2013), and the consideration of general methodological issues that those engaged in fan studies research may face (Evans and Stasi, 2014; Freund and Fielding, 2013). Rather than the consideration of identity-formation, or the experience and challenges of research, my interest is in the articulation of ethical positions in fan studies writing. By exploring the strategies by which ethical positions are established and legitimised in this scholarship, my aim is to develop some destabilising resources for those that wish to subject ethical issues to scrutiny.

The paper begins by considering why we might want to try to disrupt established thinking in our approaches to research ethics. Here I introduce two problematic tendencies that have been considered in recent work on situated ethics: the essentialising of ethical positions and over-identification with prospective points of ethical authority. I then turn to one perspective that presents a richly elaborated and forceful take on the ethics of fan studies - the idea of 'fans first' as articulated in Busse and Hellekson (2012) and in the Editorial Philosophy of Transformative Works and Cultures (Hellekson and Busse, 2009). This is used as an exemplar through which to raise questions of how ethical positions are asserted within the field. I consider the nature of the ethical guidance it presents, before reflecting on how the figures of 
the "researcher" and "fan" are established as legitimising points of reference in this work. Whilst the 'fans first' perspective is clearly not shared by all fan studies researchers, it constitutes a potent and distinctive point of authority in the literature, one whose terms continue to be refined in the ongoing development of this position (Busse, in press; also 2016).

Examining the formation of 'fans first' guidance in these two texts leads me to make two suggestions. Firstly, that whilst fan studies have focused critical attention on the essentialising moves by which "fans" are represented and discursively brought into being in different contexts (Bennett and Booth, 2016; Duits, Zwaan and Reijnders, 2014; Hills, 2012b, 2007), there is more to question about the constitution of research subjects in the discussion of ethical issues. Fan studies researchers have often been concerned with the possibility that research might "objectify" fans (Evans and Stasi, 2014). Yet from a methodological perspective, as I will suggest, adopting a research gaze can be seen to involve an inescapable objectification of the world. It is the extent to which we critically and reflexively engage with the manner in which we bring entities into being in the practice of research that therefore becomes significant. My second assertion is that whilst the ethics of fan studies has often been positioned in opposition to other research approaches, there is value in exploring the similarities between the ethical moves made by scholars both within and outside of the field. The article argues that doing so may lead us to ask productive questions of the sorts of research we are doing, and the claims that we make about this.

\section{UNSETTLING ETHICS IN FAN STUDIES}

As fields of scholarship develop, expectations regarding what constitutes ethical practice tend to form increasingly familiar and reliable patterns. Specific ideas and orientations begin to define the field, becoming more taken for granted, as ethical practices and principles become institutionalised through the regularity of publication, dissemination and community practices. Whilst such sedimentation is a characteristic of a thriving research community, it also presents potential pitfalls. 
Stephen Fuchs (2009), for example, has drawn attention to how fields of practice often slip into reliance upon the self-evidence of the "way things are" - and how the expectations of a field may become naively attributed to the world rather than to the objectifying gaze of the observer (26). Here, Fuchs can be seen to align with a call to break with the security of what Pierre Bourdieu terms "prenotions" (Bourdieu, Chamboredon and Passeron, 1968/1991), taken-for-granted ideas that may take scholarly or vernacular forms and which may trap researchers within redundant patterns of thought. Fuchs suggests that there may be particular dangers in appeals to realism - such as the attributing of certain practices or actions as inherently ethical or unethical. As he states: "any cohesiveness must be accomplished" (2009, 15). It is in this context that Fuchs posits the productivity of exploring counterintuitive premises as a way of trying to unsettle what becomes intuitive common sense thinking within the field (ibid, 48). To achieve this requires an approach that must, to some extent, run counter to the normalising and naturalising tendencies of a strongly institutionalised research programme.

As established moral norms have appeared to weaken (Bauman, 1994; Redclift, 2005) scholarly approaches to ethics have placed increasing attention upon the way that "being ethical" is achieved relationally. This emphasis is evident in writing on the ethics of social science research that has emphasised the contingent and localised nature of ethical decision-making in qualitative research (see for example Meskell and Pells, 2004; Canella and Lincoln, 2007; Calvey, 2008), as well as studies of the relationship between ethics and identity that have focused attention on individuals' "strategies for shoring up an authentic sense of self" (Benwell and Stokoe, 2006:22; see also Lebow, 2013) in the face of moral uncertainty. Here, ethical manoeuvring is configured as an ongoing struggle that occurs in relation to a complexity of contested and sometimes competing ethical domains, including personal investments and institutional frameworks (Whiteman, 2012).

The recognition of the relational nature of ethical positioning introduces a second danger in thinking about ethics: the problem of identifying too quickly with particular points of authority in the negotiation of ethical issues. In the context of research, for 
example, Canella and Lincoln (2007) warn against over-identifying with institutional ethics (such as the judgement of ethics committees); suggesting that researchers should instead endeavour to attend to a multiplicity of 'voices and positioning' (317). Similarly, Lebow $(2013,310)$ argues that whilst there are "[...] uncertainties and tensions associated with multiple, and possibly conflicting, identifications," suppressing uncertainty in order to "maintain [...] belief systems' leads to a 'unidimensional" approach. Here, over-identifying with or reifying any anchoring point in the achievement of an ethical position becomes marked as potentially dangerous. Instead; being ethical 'requires facing up to contradictions of all kinds, especially internal ones' (ibid).

Keeping these warnings in mind, I now want turn to the idea of 'fans first.' In its growing visibility and influence, this can be seen as an exemplar of the ways that ethical guidance takes root in fields of research.

\section{'FANS FIRST'}

A question from the audience in the closing ethics panel of the Fan Studies Network 2015 conference drew attention to the challenges of researching 'deviant' fan communities (those who could never be our 'fan friends'). How might we go about studying fan communities whose actions might themselves be regarded as 'unethical'? The anxiety here appeared to relate to the difficulty of aligning with a 'fans first' ethos: one that would suggest that the handling of ethical issues such as privacy and consent should be grounded in the ethical expectations of fans (Busse and Hellekson, 2012).

The idea of 'fans first' has taken different forms within fan studies; from identification with a subjective state (expressions of the idea of "being" a fan "first" commonly voiced by multiple authors to differing levels of explicitness), to a more strongly institutionalised ethical imperative that brings with it particular guidance in respect of methodological and practical action. The latter is particularly evident in the centrality of the 'fans first' ethos to the Editorial Philosophy of Transformative Works and Cultures (Hellekson and Busse, 2009). As the question posed at the 
Network conference suggested, a core idea is that the handling of ethical issues such as privacy and consent should be grounded in the ethical expectations and codes of fans who are invoked - whenever methodologically possible - as participants and equals rather than as researched parties (Busse and Hellekson, 2012; Hellekson and Busse, 2009). The aim in doing so is to produce "[...] sound, respectful, non-titillating scholarship" (Busse and Hellekson, 2012, 51).

In this focus, 'fans first' can be seen to be concerned with preventing the "wronging" as much as the "harming" of fans (Wax and Cassell, 1981). It is established in opposition to those who would neglect, exclude, expose, or exploit fan subjects/artworks, particularly outside researchers who might adopt an 'anything goes' ethos and place fan communities at risk of harm. This emic emphasis can be seen to bear a particular methodological heritage in fan studies in the historical preference for overt, participatory methods, and suspicion of covert methods (see Whiteman, 2012; 2007), and the importance of insider perspectives to the development of the field. The influence of this approach appears to be growing, with 'fans first' having been interpreted as "defining the right ways of doing things for an academic in the field of fan studies" (Musiani, 2011, np, my emphasis; see also Jones, 2015).

The 'fans first' perspective can be regarded as an important challenge to the colonising gaze of neoliberal models of ethics that adopt bureaucratic and potentially restrictive approaches towards the protection of human subjects. By emphasising ideas of respect and community, it shifts the register towards an ethics of care and collaboration that - as I will discuss in the next section - has achieved an increasing grip outside of fan studies research (see Denzin and Giardina, 2007). We might be convinced by this way of thinking about ethics and about research. Yet my call to disrupt ethics in this paper extends to all approaches and ways of thinking and this is perhaps particularly important as models of ethics grow in their influence.

In considering the terrain of guidance that the 'fans first' position sets out in these texts, it is useful to draw from a distinction that Martyn Hammersley (2014) has made in a discussion of the role of ethical principles in research. This distinguishes 
between two dimensions - the discursive force of an assertion (whether this is presented as something that might be thought about, or as a more prescriptive imperative) and the specificity of the guidance that is asserted by the principle (the level of abstraction at which it operates) (435). In its presentation, the promotion of 'fans first' can be seen to have the "discursive force" of an injunction rather than highlighting a possible consideration (Hammersley, 2014, 435). Whilst the interests of fans are presented as something that should be taken into account by researchers, the terms in which it is expressed are critical of alternatives; put simply "[...] the fans must come first" (Busse and Hellekson, 2012, 44). In relation to this dimension, it therefore appears to have strong force.

Positioning 'fans first' in relation to the second dimension is more difficult. At one level, 'fans first' appears to be relatively abstract in character. In their 2012 chapter, Busse and Hellekson argue that what putting fans 'first' actually means in practical terms is dependent on the specificities of any given study. As they say:

[...] given the range of positions among and within different fan communities and different disciplines' diverse methodologies and conduct of research, there can be no hard-and-fast rule. We thus suggest a policy that remains open enough to accommodate different scenarios while protecting fannish spaces and individual fans - as well as a researcher's code of ethics and academic rigor. (41)

Similarly, Stein and Busse (2009) draw attention to the variance in the expectations of fans and are careful to undermine monolithic notions of fan practices. The stated desire for an open policy and recognition of the heterogeneity of fan cultures here appears to reject a priori closure in what constitutes ethical action. Yet certain methodological actions are identified as being more ethical than others in a way that destabilises the certainty of this rejection. This includes the general assertion that "When writing about fans and their creations, it is not ethical to ignore fans' expectations of privacy [...]" (Busse and Hellekson, 2012, 39). More specific and concrete methodological calls are also promoted, such as that to keep fans' offline names separate from their pseudonymous identities (39), to share research with 
subjects prior to publication, and to obtain consent before citing fan works (Busse and Hellekson, 2012; TWC Editorial Philosophy). These recommendations - which, to date, have primarily focused on issues of publication and use of data - assert more specific advice that can be seen to give the 'fans first' principle "action driving capacity" (Hammersley, 2014, 438) and serve to reduce the level of abstraction at which it operates. In this way, 'fans first' conveys a clear preference for a certain type of research - insider, participatory, overt, sanctioned - working as part of a community and taking into account fannish norms/ethos, with the ethics of the researcher strongly aligned with those of the researched context.

\section{TWO REFERENTIAL ENTITIES: “RESEARCHERS” AND “FANS”}

In its generalising moves, the 'fans first' position, as presented in these texts, establishes a particular way of thinking about fans and those who study them. It suggests that researchers should afford fans a concern that marks them as different from other human subjects, and establishes fan scholars as being different from other researchers (Musiani, 2011, np). What I want to do now is to think about how this positioning is achieved - and how the idea of "the researcher" and "the fan" emerge in this writing.

In each case, the invoking of these points of reference involves an objectification that is inescapable when we take up the position of observer or commentator (Dowling and Brown, 2009, 7). This is an important point: one of the dangers Fuchs notes is of the researcher seeing themself as speaking for the object in a way that fails to acknowledge the recontextualisation that any research gaze involves. In the field of audience research, Barker has written about the need to pay attention to the discursive "figuring" of the audience, and how these "tie together webs of enthymematic premises in ways which make them hard to argue with [...] it has become one task of audience research to take those suppressed premises, to tease them apart, and to try to render them testable." $(2013,72)$ Here my interest is in a teasing apart of how these objectifying representations are used to anchor ethical positions, in order to demonstrate the constructions that underpin ethical manoeuvres within 'fans first' discourse and beyond. 


\section{RESEARCHERS}

A number of things are striking about the way that 'fans first' constitutes the figure of non-fan studies research/researchers as an anchoring point. Whilst it establishes alliances with feminist and qualitative approaches to research (Musiani, 2011) and directs fan scholars to the ethical guidance of groups such as the Association of Internet Researchers, it is notable that in the articulation of 'fans first' as an ethical code, a rather dystopian vision of some forms of 'research' is used to establish the truth of ethical ambition, and relationally establish the positive status of fan academics. TWC's statement of Editorial Philosophy, for instance, juxtaposes the ethics of fan studies with the practices of nonfan/outsider researchers, suggesting that "fans can do a better job of writing academic works about fandom than nonfans" or "random outsiders" or "academic interlopers" might do (Hellekson and Busse, 2009). This call to participatory scholarly action sets fannish concern in opposition to an academic mandate that is configured as adopting the form of exploitation.

Elsewhere, the articulation of the 'fans first' position has been expressed via reference to, and in opposition to, classic cautionary tales of "careless research" such as Laud Humphreys' controversial Tearoom Trade study (Busse and Hellekson, 2012 , 46) and more recent studies of fans that incensed fan communities and produced "deceptively and faultily gathered material" (ibid, 46-47; a specific target of criticism being Ogas and Gaddam, (2011)). Here we have a move from individual studies whose status may or may not be regarded as unethical (see, for example, Babbie (2004) and Schacht (2004) on the contested debates regarding the ethical status of Humphrey's work) towards a marking of external, non-fan academia as

parasitic - "[...] a non-reciprocal, subtractive relationship with an unwilling or nonconsenting host" (Burton and Tam, 2015, 2).

Given the ways that fans have been treated in the past by some researchers, the concerns here are understandable. Yet there are dangers in this characterisation, and perhaps value in Burton and Tam's call to challenge "automatic negative sociocultural/socio-economic and ethical judgements of parasitism" and to advocate "an 
ethics of hesitation, a reservation of judgement, in situations where apparent instances of parasitism present themselves." $(2015,3)$. To consider the potential value of research that does not appear to give back to the community, for instance, or to take seriously the potential for an outsider position to be useful in the engaging with ethical questions. It could also be argued that such positioning - in establishing such a strong opposition to other research approaches - might be seen to replicate the pathologising of groups that fan studies researchers have worked to challenge in relation to negative characterisations of fans (and fan studies) in the media and beyond. The target in this case (distanced non-fan scholars) is constituted as an illegitimate point of authority and a legitimate (less vulnerable) object of criticism.

Yet there is a more general concern here. From an outsider position we might examine more closely than has been done to date the continuities between the ethical considerations of 'fans first' and other slides towards purely emic approaches beyond the field of fan studies. These include the call for Internet researchers to put the human-subject at the 'heart' of their projects (Markham, 2005), and the tracing of moves within qualitative research towards a 'new' ethics focused on notions of care, justice and 'coequal' relations between researcher and researched (see Hammersley and Traianou, 2014). Such approaches have seen terms such as solidarity and 'love' (ibid) entering into discussions of ideal research relationships in a manner that shifts qualitative researchers towards a fannish register in talking about methods.

In particular, the brunt and manner of attacks on neoliberal models of ethics in this work is similar to the criticism of external 'research' in 'fans first' discourse: for example, writing on the "abject poverty" of the human-as-subject model as it has become realised in neoliberal regulative bureaucracy via the institutionalised practices of "neofascist state apparatuses" (Denzin and Giardina, 2007, 29). Alternatives presented in this writing include calls for researchers to make "radical democratic practices work" (ibid, 13), to learn "from indigenous scholars" (13), to engage in participatory modes of knowing led by communities (14), and to engage in collaboration and dialogue (15) that shifts scholars from research 'on' to research 
'with.' In each case the call to situatedness involves a collapse of the research regard to stand with the researched: one in which the otherness of the researched cannot be preserved.

Looking beyond the field of fan studies in this way might also lead us to ask difficult questions of the nature of participation and collaboration that we offer to others in our research. Here, critiques of the growing use of 'participatory' discourse particularly the use of participatory rhetoric as a shield (McQuarrie, 2014) - have the potential to bite. There is a pervading unease about the recruitment of this term in recent literature - see especially the thoughtful discussion in Jenkins et al. (2015). Might such thinking be extended towards our own research practices and ethical thinking? As Larsen and Zubernis note, it has been argued that once you start writing, one is no longer a 'fan first' $(2012,6)$. My argument is that fandom and research are different practices that present different demands in terms of consistency, reflexivity and the ability to look across settings. This raises an immediate ethical concern:

In some ways, the pretence of participation is more troubling than the absence of participation. When authentic participatory energy turns out to be little more than democratic window dressing for top-down decision-making, those who devoted time and energy to the process might walk away feeling cynical, hopeless, and discouraged. (Jenkins, 2013, np).

An important question here, then, is how radical in its approach participatory fan studies research is when it maintains the author-ity of the individual: the fan academic whose work is permitted and approved by fans and therefore continues a stance of speaking on behalf of fans, from a position of insider authority (as-a-fan)? Does the focus on issues of consent and use of data limit the moves that we are making in this direction? Are we seeking to maintain authorial security that more radical perspectives would perhaps deny?

\section{FANS}


As the name 'fans first' suggests, the fan emerges as a key point of attribution in respect of ethical positioning in this model. Yet the stability of this point of reference, like that of the "researcher," can be unsettled.

Busse and Hellekson $(2012,38)$ make the case that "fans and fan artworks ought to be treated differently than the traditional model for freely accessible texts." This is because the nature of fans' interests and engagements mark them as particularly vulnerable; "real harm, such as loss of livelihood, could come to them if the researcher is not careful." (39) Again, care is taken to confirm that a particular type of fan is being invoked in this work. In an interview with Henry Jenkins, Busse and Hellekson describe how they are working with a relatively "narrow" definition of the fan - one that would exclude the idea of fans of "stamp collecting or sports" for instance (Jenkins 2014, np.). They note:

[...] we are primarily focused on what Coppa has termed [...] "media fandom" i.e. creative fan works for Western live-action shows and connected fandoms. That means that we purposefully limited ourselves, but it also means that we can focus on a given field and explore it in all its facets and with all these different approaches" (Busse and Hellekson in Jenkins, 2014, np).

This fan is invoked in terms of a sensitivity of expectations and desires that might inform methodological decision making. This includes the expectation that fans expect privacy, perceiving "the space where they create their artworks as closed" (Busse and Hellekson, 2012, 38). They argue further that "[...] many fans find unacceptable the notion that their works may be freely perused by outsiders" (39), and that "[...] from the point of view of the fan, it would not be a good idea to scan the documents and put them online [...]" (43). Busse and Hellekson also suggest that the fact that fans limit access to their work "indicates that many fans prefer their spaces to remain out of the public eye" (46). This judgement is based on the authors' knowledge of, and interactions with, members of the fan communities that they are themselves participants within; this embodied knowledge enabling the presentation of what members expect. As noted earlier, however, Busse and Hellekson also suggest that there is variance in the expectations of fans: 
"[...] fandom is hardly a monolithic creation: every fandom has different rules and expectations, some of which touch on privacy. It is important to learn what these are and how to negotiate them, so that fans and their communities can be treated respectfully. This aspect of research is just as important as knowing the ethical, citation, and human-subjects standards in one's own field, be it English, sociology, or media studies" $(2012,51)$

In general terms, 'fans first' is therefore presented as being informed by the varying expectations of fans who are positioned as equivalent both to each other (in their shared desires and concerns as bonded within specific fandoms) and to fan scholars (as equally authoritative sources of ethical guidance).

I now want to consider how this fan, with their desires and ethical status, is brought into being as a known/knowable entity in order to legitimise and promote certain methodological decisions. As introduced above, the invoking of the authentic beingness of fans that I am tracing here extends beyond 'fans first' discourse. It is evident, for example, in the methodological discussion of the risk of "losing" the fan in textual approaches to research (the risk of "making them merely a subject created through textual functions" (Evans and Stasi, 2014, 12)); and in criticisms of psychoanalytic approaches to fan studies research (where the "fan is again a spectator position, not a lived experience" (ibid, 12)). Yet, in each case, the bringing into being is clearly based on the authors' objectifications of fan practices and participants.

We can see this ontologising strategy extend into approaches that take different stances to 'fans first'. For instance, Jonathan Gray's work on 'antifan' sentiments on Television Without Pity (TWoP) (Gray, 2005) - a site that he studied without permission. He describes how he did not feel "as though I was intruding or violating any trust by doing so" because:

[...] TWoP is a site of gargantuan size, with thousands of viewers passing through it [...] Posters are fully aware of the public, open nature of the forum; most use pseudonyms, meaning they are both aware of speaking potentially to thousands and already reasonably 
anonymous; and the performative nature of much TWoP commentary itself belies an awareness of (or even a desire for) a considerable audience. In addition, as I soon learned, the large thoroughfare produced little sustained interaction by a close-knit group and, thus, renders itself unsuitable for dense textual-psychological examination; therefore, this study represents a broad overview of expressions of antifandom, not an intimate or incisive look at the individual posters and their elaborated thought processes. As does all audience research, I am studying the textualised output and versions of the TWoP posters, not the people themselves. (Gray, 2005: 847)

Here, Gray does not equate the textualised output of fans with the fans themselves, as Busse and Hellekson (2012) do in arguing for fans/fan works to be afforded the same protections. We can see in this account an inverse of the positioning within 'fans first' discourse - the expectation of fans that sites are public rather than private, and the sense that they are talking to an open audience (rather than the closed context suggested in the 'fans first' approach).

These approaches are therefore different in terms of how they represent fans and use their perceived expectations to inform research practice. Yet, in each case, fans are constituted as relatively stable and reliable points of authority through a process of hypostatisation that involves an attribution of natural rights. Each invokes "the inalienable rights of humans qua human, embodied in their being" (Dudley-Smith, $2015,25)$ that we often see voiced in relation to the protection of other vulnerable groups at certain points of development, such as children (ibid). This is more explicit in 'fans first' discourse, but also implied in Gray's quotation (the suggestion that if one were studying "individual posters and their elaborated thought processes," decisions would be different).

If our aim is to disrupt ethical thinking, the attribution of such rights might be purposefully unsettled. As has been much commented on (see also Dowling and 
Brown, 2010), the attribution of natural rights leads to certain restrictions. As Dudley-Smith argues:

One problem with the idea of natural right is that it tends to see individuals as the exclusive holders of right - so that collective rights only exist if they are consonant with those of the individual. Such a position also tends to close down the opportunities for research to those involving full understanding by the researched of the nature of the research. In the limit such understanding would seem difficult to realise without extended apprenticeship. $(2015,25)$.

Perhaps we might challenge the coherence and stability of fans as equivalent desiring persons? That view might be seen to mythologize the ontology of the person and thus downplay the contingencies intrinsic in the practices in which that personhood is able to be expressed.

We could go further to challenge the research notion that fan subjects constitute reliable, knowable entities, and draw attention to the ways that we are imagining them. Significantly, this challenge can also be addressed at those promoting ethics of care/love and indigenous ethics outside of fan studies. Again, stepping out of the field can provide resources to unsettle this. We might consider, for instance, whether related fields, such as that of audience research, have perhaps been more assertive about problematising the stability of the central referent of the "audience" than those writing on fans in fan studies. The development of that field has seen an intense destabilisation of that reference point and awareness of its discursively constructed nature, presenting the idea that the only existence that the audience has is that of an 'imaginary entity' (Ang, 1991). Fan scholars have worked to unsettle the referential fixity of the 'fan' as an anchoring point by focusing attention on the discursive construction of this referential object. Assessments of the ability of the notion of the fan to maintain conceptual grip as it becomes increasingly "elastic" (Jenkins, 2007), along with work on the articulation of competing "visions of fandom" (Stanfill, 2013) within and outside of fan communities, and calls to consider how particular realisations of fandom are given/denied representation in academic 
scholarship (Hills, 2012a), demonstrate this emphasis. Yet when we look at accounts of methodological decisions in fan studies research, "fans" are often used as a more unproblematic referent.

One useful way of breaking with these research imaginaries is to examine examples that appear to present subjects that are more difficult to form into fleshy knowable subjects. The move to online domains, and the way that the coherence of the individual is challenged in technologically mediated spaces, can be seen to unsettle the certainties of offline identities that perhaps inform the consideration of fans as subjects. One arena that is salient here is the discussion of Uniform Resource Identifiers in writing on big data research, and consideration of the way that this brings data entities (such as people and places) into being (Halford, Pope and Weal, 2012, 177-178). As these authors note, whilst "the naming of data entities may appear to be straightforward," it assumes that "real world things" are objectively knowable, autonomous and independent (178), assumptions that stand "[...] in stark contrast to relational ontologies which insist that entities are produced through their relations with other entities in particular networks and contexts." (ibid). The move to relationality in the constitution of the research gaze is exemplary for interrogating how we invoke subjects-as-entities in our own research practices, and the assumptions that we bring to bear in doing so.

Empirical studies of fan practices that challenge the apparent reliability of conventional research subjects are also salient here. Studies that look at characterrole play accounts in social media provide one example (Bore and Hickman, 2013a, 2013b; Booth, 2008). In Bore and Hickman's (2013a) study of fan tweeting as characters, for instance, the authors note how:

"Our analysis of the Twitter data and the interview data provided us with two different sets of voices; the constructed Twitter voices of the characters and the e-mail voices of the fans behind the Twitter accounts. [...] The duality of the character/fan identity presented a particular challenge in the case of our interview with @ElsieSniffin, who chose to conduct the entire interview in 
character, apart from certain 'off the record' comments." (Bore and Hickman, 2013a, np)

This duality can be seen both as an artefact of the productive research gaze - with both the Twitter personas and fan identities brought into being by the disciplined regard of the researcher - and as providing a way of problematising moves to essentialise or reify participants as knowable. Looking to such examples does not involve the claim that the idea of the fan has no value; but serves to problematise its use as a resource in respect of establishing the ethicality of research practice.

\section{CONCLUSION}

Jenkins writes about the tendency to see fan studies "as a somewhat specialized, narrowly defined body of research" $(2007,363)$, noting that "We fail if we simply circle around the same theories and the same debates, if we introduce no new concepts and few new arguments to the stew." (363) In this paper I have attempted to introduce new arguments by arguing for the value of pursuing disruptive and counterintuitive thinking in relation to emerging ethical ground rules.

Examining the 'fans first' position enables a consideration of issues that I would suggest are key in terms of the future development of research ethics in fan studies. From a disciplinary perspective this includes the promotion of, and investment in, specific ethical principles as guidance for research practice; the way that specific ideas and orientations start to define the ethics of a given field of scholarship as ethical practice becomes institutionalised through a regularity of practice; and how this is then used to mark the identity of our field of research as distinct from other fields of academic practice. At a more localised level it raises questions about how the other informs one's ethical stance (even if the other and self are positioned as aligned), and the manner by which anchoring points of reference - such as the figure of the "fan" and what "it" desires - are imagined and recruited in the legitimisation of our ethical stances. 
'Fans first' provides a valuable focus for the consideration of these questions because it is an elaborated, developing line of argument that casts competing approaches (such as 'anything goes' perspectives, or technical approaches to the public status of online material that might mark the world in black and white) in an impoverished light. As the intricacies and challenges of 'fans first' continue to be explored (see Busse, in press), I have argued for the value of this position in provoking reflection both on our research practice and the identifications and entities that emerge within the fan studies literature. This paper suggests that the attention afforded to how we construct the object of fan studies should be extended to confront the objectification of fans in the positing of ethical guidance and articulating of ethical principles, particularly when this is used to stipulate "correct" methodological actions, or demonstrates a strong identification in relation to one potential point of ethical authority.

At the heart of such moves is a notion of fans/subjects often as relatively stable or coherent entities and as themselves ethical. I have suggested that such notions must be problematised. Within online environments the notion of the fan or subject can be undermined by the uncertainty of authorship, yet even when we are dealing with the embodied subject of the offline world, the apparent solidity of those we research can be regarded as illusory. Within this context, the attribution to, or denial of, ethical value to subjects can lead us into problematic positions; there are always dangers in attributing positive or negative values to others. At the same time, overidentification with the subjects that are drawn into our research gaze might lead us towards unethical practices. As Hammersley has noted, the focus on harm in an ethics of care requires distance; "[...] there may be different views about what counts as well-being, and how it is to be determined, including about whether we must always accept people's views about their own well-being [..]." $(2015,436)$.

Stepping further back, situating 'fans first' within a consideration of the sedimentation of ethical guidance in fan studies raises further issues. Whilst the focus of ethical critiques has often been on restrictive, bureaucratic and neoliberal models of ethics, the possibility exists that alternative models can also slip into forms 
of regulation. Alternative frameworks also have the potential to "deform the way that researchers think about their value commitments and act on the basis of these: not least because [they require researchers] to embrace the pretence that their ethical judgements can and should be governed by commands, rules or principles." (Hammersley, 2015, 444) Such rules do not only have to be bureaucratic ones: pressure can be felt in other ways and in respect of ethics there is always the danger of a "compliance culture" in which "being 'ethical' becomes equated with conformity (444). The concern voiced at the Fan Studies Network conference about how we might put "unethical" fans 'first,' perhaps reflects this pressure to conform. As I have argued, adopting a disruptive stance, and looking towards external research

perspectives whilst recognising continuities between debates and practices in different arenas, provides a way of 'unsettling relations' that would seem to be a vital move in this context.

\section{ACKNOWLEDGEMENTS}

I would like to thank Jessica Bain, Kristina Busse, Russell Dudley-Smith and Katherine Larsen for their insightful comments on earlier drafts of this paper.

\section{REFERENCES}

Ang, len (1991) Desperately Seeking the Audience, London/Routledge.

Babbie, Earl (2004),"Laud Humphreys and research ethics", International Journal of Sociology and Social Policy, 24(3/4/5): $12-19$.

Barker, Martin (2013) Finding Audiences for Our Research: Rethinking the Issue of Ethical Challenges. The Communication Review, 16:70-80.

Bauman, Zygmunt (1994) Alone Again: Ethics After Certainty. London: Demos Papers.

Bennett, Lucy and Paul Booth (2016) Seeing Fans: Representations of Fandom in Media and Popular Culture, Bloomsbury. 
Benwell, Bethan and Elizabeth Stokoe (2006) Discourse and Identity. Edinburgh: Edinburgh University Press.

Booth, Paul (2015) "Reifying the Fan: Inspector Spacetime as Fan Practice," Popular Communication: The International Journal of Media and Culture, 11(2): 146-159.

Booth, Paul (2008) Rereading Fandom: MySpace Character Personas and Narrative Identification, Critical Studies in Media Communication, 25(5), 514-536.

Bore, Inger-Lise Kalviknes and Jonathan Hickman (2013a) "Studying Fan Activities on Twitter: Reflections on Methodological Issues Emerging from a case study on The West Wing fandom", First Monday, 18(9), np.

Bore, Inger-Lise Kalviknes and Jonathan Hickman (2013b) "Continuing The West Wing in 140 Characters or Less: Improvised Simulation on Twitter" Journal of Fandom Studies, 2(1) 219-238

Bourdieu, Pierre., Jean-Claude Chamboredon, and Jean-Claude Passeron (1968/1991), The Craft of Sociology: Epistemological Preliminaries, Berlin: de Gruyter.

Burton, James and Daisy Tam (2015) "Towards a Parasitic Ethics" Theory, Culture \& Society, 0(0): 1-23.

Busse, Kristina (in press) The Ethics of Studying Online Fandom, in Suzanne Scott and Melissa Click (eds) The Routledge companion to media fandom.

Busse, Kristina (2016) "The Ethics of Studying Online Fandom," paper presented at Ethics and Fan Studies Roundtable, Society for Cinema and Media Studies Annual Conference, March 29-April 3, Atlanta.

Busse, Kristina and Karen Hellekson (2012) "Identity, Ethics, and Fan Privacy" in Katherine Larsen and Lynn Zubernis (eds.) Fan Culture: Theory/Practice, Newcastle: Cambridge Scholars Publishing, pp. 38-56. 
Busse, Kristina and Jonathan Gray (2014) "Fan Cultures and Fan Communities", in Virginia Nightingale, The Handbook of Media Audiences, John Wiley \& Sons, pp 425440.

Calvey D (2008) The Art and Politics of Covert Research: Doing 'Situated Ethics' In the Field. Sociology 42(5): 905-918.

Canella, G S and Lincoln Y (2007) Predatory vs. Dialogic Ethics: Constructing an Illusion or Ethical or Ethical Practice as the Core of Research Methods. Qualitative Inquiry 13(3): 315-335.

Denzin, Norman K and Michael D. (2007) Ethical Futures in Qualitative Research: Decolonizing the Politics of Knowledge, Walnut Creek, CA: Left Coast Press.

Dowling, Paul and Andrew Brown (2010) Doing Research/Reading Research: ReInterrogating Education, London and New York: Routledge.

Dudley-Smith, Russell (2015) "Continuities and Discontinuities in the Formation, Stabilisation and Destabilisation of Three Elite School Identities in Relation to Global Change", unpublished PhD thesis, UCL Institute of Education.

Duits, Linda, Koos Zwaan and Stijn Reijnders (eds) (2014) The Ashgate Research Companion to Fan Cultures, Routledge.

Evans, Adrienne and Mafalda Stasi (2014) "Desperately seeking methodology: New directions in fan studies research." Participations: Journal of Audience \& Reception

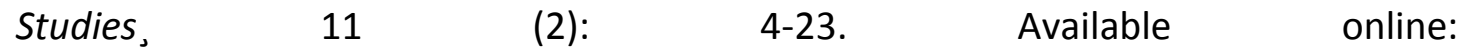
http://www.participations.org/Volume\%2011/Issue\%202/2.pdf

Freund, Katharina and Dianna Fielding (2013) "Research ethics in fan studies" Participations: Journal of Audience and Reception Studies, 10(1), Available online: http://www.participations.org/Volume\%2010/Issue\%201/16\%20Freund\%20Fielding \%2010.1.pdf 
Fuchs, Stephen (2009) Against Essentialism, Cambridge, US: Harvard University Press.

Garfinkle, Harold (1967) Studies in Ethnomethodology, Englewood Cliffs, NJ: Prentice Hall.

Gilbert, Anne (2015) What we talk about when we talk about bronies, Transformative Works and Cultures, Vol 20, http://journal.transformative works.org/index.php/twc/article/view/666/549

Halford, Susan, Catherine Pope and Mark Weal (2012) “Digital Futures? Sociological Challenges and Opportunities in the Emergent Semantic Web" Sociology 41(1) 173189.

Hammersley, Martyn (2014) "On ethical principles for social research," International Journal of Social Research Methodology, 18(4): 433-449.

Hammersley, Martyn and Anna Traianou (2014) An Alternative Ethics? Justice and Care as Guiding Principles for Qualitative Research, Sociological Research Online, 19(3), 24. Available online: http://www.socresonline.org.uk/19/3/24.html last accessed 10 June 2016.

Hellekson, Karen and Kristina Busse (2009) Fan Privacy and TWC's Editorial Philosophy, http://www.transformativeworks.org/twac/twc-citation/ last accessed $14^{\text {th }}$ June 2016.

Hills, Matt (2012a) "'Proper Distance' in the Ethical Positioning of Scholar-Fandoms: Between Academics' and Fans' Moral Economies?" in Katherine Larsen \& Lynn Zubernis (eds), Fan Culture: Theory/Practice. Newcastle: Cambridge Scholars Publishing, pp 14-37.

Hills, Matt (2012b) “'Twilight' Fans Represented in Commercial Paratexts and InterFandoms: Resisting and Repurposing Negative Fan Stereotypes" in Morey, Anne, 
Genre, Reception, and Adaptation in the 'Twilight' Series, Farnham and Burlington: Ashgate, pp 113-129.

Hills, Matt (2007) “Michael Jackson Fans on Trial? 'Documenting' Emotivism and Fandom in Wacko About Jacko," Social Semiotics, 17(4): 459-477.

Jenkins, Henry (2014) “Where fandom studies came from: An interview with Kristina Busse and Keren Hellekson (Part One)" Available online: http://henryjenkins.org/2014/11/where-fandom-studies-came-from-an-interviewwith-kristina-busse-and-karen-hellekson-part-one.html last accessed 10 April 2016.

Jenkins, Henry (2013) "What Do We Now Know About Participatory Cultures: An Interview with Aaron Delwiche and Jennifer Jacobs Henderson (Part One)"; Available online: $\quad$ http://henryjenkins.org/2013/05/what-do-we-now-know-aboutparticipatory-cultures-an-interview-with-aaron-delwiche-and-jennifer-jacobshenderson-part-one.html\#sthash.0ltbSApT.dpuf last accessed 8 April 2016.

Jenkins, Henry (2007) "Afterwards: The Future of Fandom" in Gray, Jonathan, Cornell Sandvoss and C. Lee Harrington (2007) Fandom: Identities and Communities in a Mediated World, London and New York: New York University Press, pp: 357-364.

Jenkins, Henry, Mizuko Ito and danah boyd (2016) Participatory Culture in $a$ Networked Era: A Conversation on Youth, Learning, Commerce, and Politics, Cambridge and Malden MA: Polity Press.

Jones, Bethan (2015) "Aca-Fan Research on Fannish Sites: Ethical and Moral Challenges to Using Social Media, " Available online: https://bethanvjones.wordpress.com/2015/04/03/aca-fan-research-on-fannishsites-ethical-and-moral-challenges-to-using-social-media/, Last accessed 10 June 2016.

Larsen, Katherine and Lynn Zubernis (2012) "Introduction," in Larsen and Zubernis (eds) Fan Culture: Theory/Practice, Cambridge Scholars Publishing, pp. 1-13. 
Larsen, Katherine and Lynn Zubernis (2013) Fangasm: Supernatural Fangirls, lowa City: University of lowa Press.

Lebow, Ned (2013) "Internal Borders: Identity and Ethics," Global Society, 7(3): 299318.

Markham, Annette. (2005). "The politics, ethics, and methods of representation in online ethnography." In Denzin, N. \& Lincoln, Y. (Eds.). Handbook of Qualitative Research, 3rd Edition (pp. 793-820). Thousand Oaks CA: Sage.

Meskell L and Pels P (2005) Embedding Ethics. Oxford and New York: Berg.

Musani, Francesca (2011) "Editorial policies, 'public domains,' and acafandom," Transformative Works and Cultures, Vol 7. Available online: http://journal.transformativeworks.org/index.php/twc/article/view/275/224 last accessed 18 April 2016.

McQuarrie, Michael (2014) "Democratizing Inequalities," Participation Now. Available online: https://www.opendemocracy.net/participation-now/michaelmcquarrie/democratizing-inequalities last accessed 30 June 2016.

Ogas, Ogi and Sai Gaddam (2011) A Billion Wicked Thoughts: What the World's Largest Experiment Reveals about Human Desire, Boston: Dutton.

Phillips, Tom (2013) 'Fandom and Beyond: Online Community, Culture and Kevin Smith Fandom, PhD Thesis, University of East Anglia, available online https://ueaeprints.uea.ac.uk/49704/1/2013PhillipsTPhD.pdf

Redclift, Nannekke (ed.) (2005) Contesting Moralities: Science, Identity, Conflict. London: UCL Press.

Schacht, Steven (2004) "Moving beyond the controversy: remembering the many contributions of Laud Humphreys to sociology and the study of sexuality", International Journal of Sociology and Social Policy, Vol. 24 Iss: 3/4/5, pp.3-11 
Stanfill, Mel (2013) “They're Losers, but I know Better': Intra-Fandom Stereotyping and the Normalization of the Fan Subject," Critical Studies in Media Communication, 30(2): 117-134.

Stein, Louisa and Kristina Busse (2009) "Limit Play: Fan Authorship between Source Text, Intertext, and Context," Popular Communication, 7: 192-207.

Wax, Murray and Joan Cassell (1981) "From Regulation to Reflection: Ethics in Social Research," The American Sociologist, 16(4): 224-229.

Whiteman, Natasha (2012) Undoing Ethics: Rethinking Practice in Online Research, New York: Springer.

Whiteman, Natasha (2007) The Establishment, Maintenance and Destabilisation of Fandom: A study of two online communities and an exploration of issues pertaining to internet research.' PhD thesis, Institute of Education, University of London, Available online http://www.pauldowling.me/studentswork/whiteman(2007).pdf

Williams, Rebecca (2015) Post-object Fandom: Television, Identity and Self-Narrative, New York and London: Bloomsbury. 